\title{
Modified Dual-Band Stacked Circularly Polarized Microstrip Antenna
}

\author{
Guo Liu, Liang Xu, and Yi Wang \\ Institute of Radio Wave Propagation, School of Science, Xidian University, Xian, Shaanxi 710071, China \\ Correspondence should be addressed to Guo Liu; liuguosgg@hotmail.com
}

Received 22 November 2012; Revised 25 February 2013; Accepted 19 March 2013

Academic Editor: Atif Shamim

Copyright (C) 2013 Guo Liu et al. This is an open access article distributed under the Creative Commons Attribution License, which permits unrestricted use, distribution, and reproduction in any medium, provided the original work is properly cited.

\begin{abstract}
A novel high-performance circularly polarized (CP) antenna is proposed in this paper. Two separate antennas featuring the global positioning system (GPS) dual-band operation $(1.575 \mathrm{GHz}$ and $1.227 \mathrm{GHz}$ for L1 band and L2 band, resp.) are integrated with good isolation. To enhance the gain at low angle, a new structure of patch and two parasitic metal elements are introduced. With the optimized design, good axial ratio and near-hemispherical radiation pattern are obtained.
\end{abstract}

\section{Introduction}

Satellite positioning systems are widely used in the military and civil applications. In the world, there are four satellite positioning systems such as GPS of USA, GLONASS of Russia, GALILEO of Europe, and BD of China. But among them, GPS is the most widely used currently. The antenna used for this application can be implemented in many different types. A microstrip antenna topology was selected because of its well-known advantages of lightweight, low profile, low cost, and ease of fabrication. There are many reports in the related fields [1-3]. In the literature [4], a three-layer dualfeed stacked microstrip antenna was designed with thickness more than half a wavelength. Nowadays, there are more critical requirements for the antennas such as dual-band operation, better low angle radiation pattern, and improved circular polarization level, which are even more difficult to realize. Many methods were used to widen beams and enhance the gain at low angle, for example, using high permittivity substrates, operating at higher-order modes, and using four circular slot ring arrays [5-7].

In this paper, a novel technique to generate $\mathrm{CP}$ radiation and widen the beam width of the antenna is presented. Practically, two compact stacked GPS circularly polarized antennas with near-hemispherical coverage pattern have been successfully implemented. The two modified square patches are designed at $1.575 \mathrm{GHz}$ (L1 band) and $1.227 \mathrm{GHz}$
(L2 band), respectively. The bottom antenna is used at L2 band and the top one at L1 band. Both antennas are with righthand circular polarization (RHCP). In addition, two parasitic metal elements are used to modify the antenna radiation pattern at low angle. As a result, the radiation patterns are improved significantly, especially for nonideality of the pattern in the $x-y$ plane at low angle. Details of the antenna design are described, and measured results are shown. The comparisons of radiation patterns for the antennas with and without the parasitic metal strips are presented and discussed.

\section{Design of Antenna}

It is well known that various single-feed microstrip antenna configurations can be used to generate circular polarization $[8,9]$. Some of them are obtained by modifying the square microstrip antennas. These include diagonally fed nearly square, square with stubs and notches along the two opposite edges, corner-chopped squares, and squares with a diagonal slot.

In this paper, two upright metal strips at two opposite corners are used to create circular polarization radiation for the L1 band antenna as shown in Figure 1. The dimensions of the antenna patch and ground plane are $a_{1}$ and $b_{1}$, respectively. The width and the height of the metal strips are $w_{1}$ and $h$. In fact, this is a modification of the typical square patch with stubs at two diagonal corners [9], and it also contributes to the 


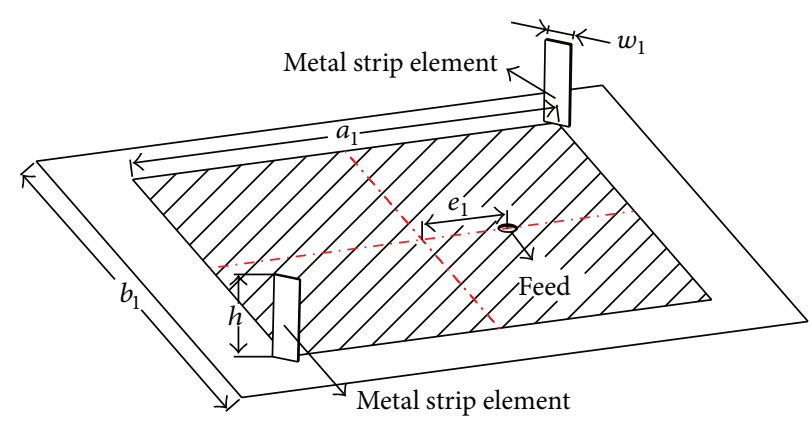

FIgURE 1: Configuration of the L1 band antenna.

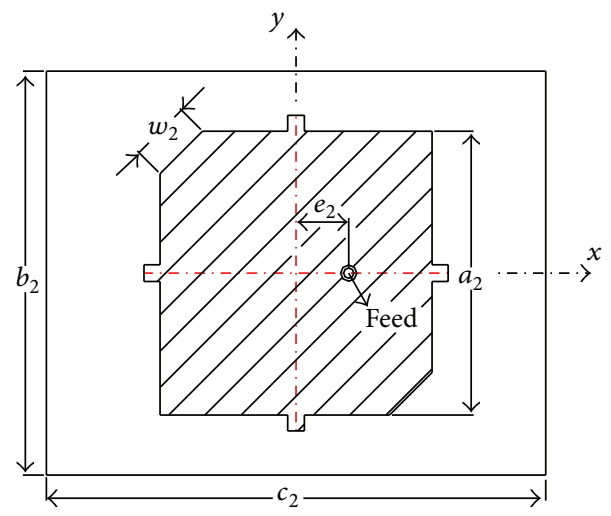

Figure 2: Configuration of the L2 band antenna.

improvement of the antenna radiation pattern at low angle as shown in Figure 4. The corner-chopped square microstrip antenna with the stubs on the four edges is adopted for L2 band. The side length of the patch is $a_{2}$, and that of the ground plane is $b_{2}$ and $c_{2}$ as shown in Figure 2. The substrate between the patch and the ground plane is Rogers RT/Duroid 6010, which has a dielectric constant of $\varepsilon_{r}=10.2$, dissipation factor of 0.0023 , and thickness of $3 \mathrm{~mm}$.

The two antennas are stacked together and covered in an ABS plastic radome, which has a dielectric constant of 2.3, loss tangent of 0.0025 , size of $a_{3} \times b_{3} \times c_{3}$, and a thickness in the top portion of $0.9 \mathrm{~mm}$. Studies indicate that this material has little influence on the antenna performance for the designed two bands. To reduce the interference between the two antennas and get a good isolation, they are separated with a $2 \mathrm{~mm}$ air gap. In addition, the high-band antenna is fed upside down, which means that the radiating patch element was connected to the feed cable ground, and its ground plane was connected to the inner conductor of the feed cable as illustrated in Figure 3(a). In this way, the coupling between the two antennas can be reduced significantly.

A significant contribution in this design is the improvement of the antenna radiation pattern. For obtaining a good hemispherical pattern, two parasitic elements are added above the antenna along with the narrow side, and they are attached to the inside surface of the radome as shown in Figure 3(a). These two elements are made of flex printed circuit. It does improve the antenna radiation at low angle.
The proposed antenna has been designed and optimized using the software Ansoft HFSS. The final dimensions of the optimized antennas are as follows: $a_{1}=26.8 \mathrm{~mm}, b_{1}=$ $31.6 \mathrm{~mm}, e_{1}=6.5 \mathrm{~mm}, w_{1}=1.84 \mathrm{~mm}, h=4.8 \mathrm{~mm}, a_{2}=$ $32.8 \mathrm{~mm}, b_{2}=48.6 \mathrm{~mm}, c_{2}=60.8 \mathrm{~mm}, e_{2}=8.1 \mathrm{~mm}, w_{2}=$ $7.2 \mathrm{~mm}, d=2 \mathrm{~mm}, w_{3}=2.1 \mathrm{~mm}, a_{3}=76 \mathrm{~mm}, b_{3}=52 \mathrm{~mm}$, and $c_{3}=20 \mathrm{~mm}$. The photograph of the finished antenna is shown in Figure 3(b).

\section{Results and Discussions}

The measurements were performed with Agilent $8753 \mathrm{ES}$ vector network analyzer and in Airlink 3D anechoic chamber. The simulated and measured VSWR of the two antennas are presented in Figure 5. It can be seen that the two antennas are tuned with excellent impedance matching at the required frequencies and the measured impedance bandwidth (VSWR $\leq 1.5: 1$ ) is $3.2 \%$ and $3.1 \%$ for the $\mathrm{L} 1$ and $\mathrm{L} 2$ band antennas, respectively.

The radiation patterns for the L1 and L2 bands with and without the two parasitic metal strips are shown in Figures 6 and 7. It is easy to see that the radiation patterns of antennas without parasitic metal strips are not symmetric especially in the $x-z$ plane because of the size restrictions for both antennas, and the low angle radiation is a bit weak. After adding the metal strips, it is very clear that the patterns in the low elevation are much better than before, and they are more omnidirectional and symmetric. This is due to the fact 


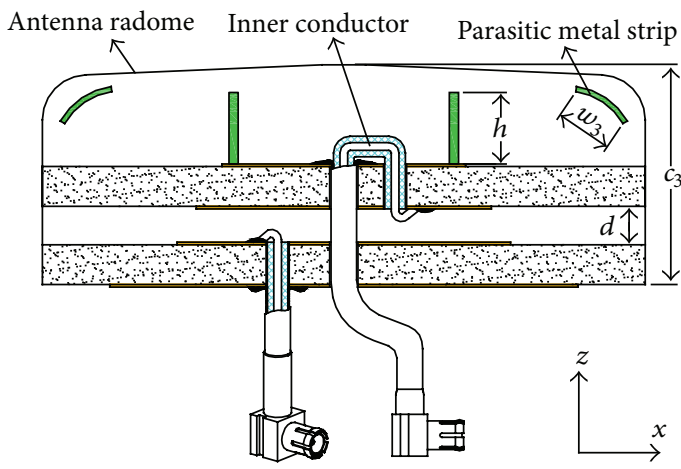

(a)

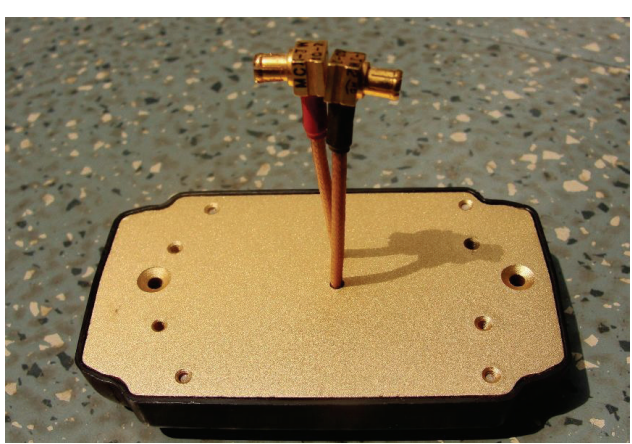

(b)

Figure 3: (a) Geometry of the proposed antenna, (b) photograph of the fabricated antenna.

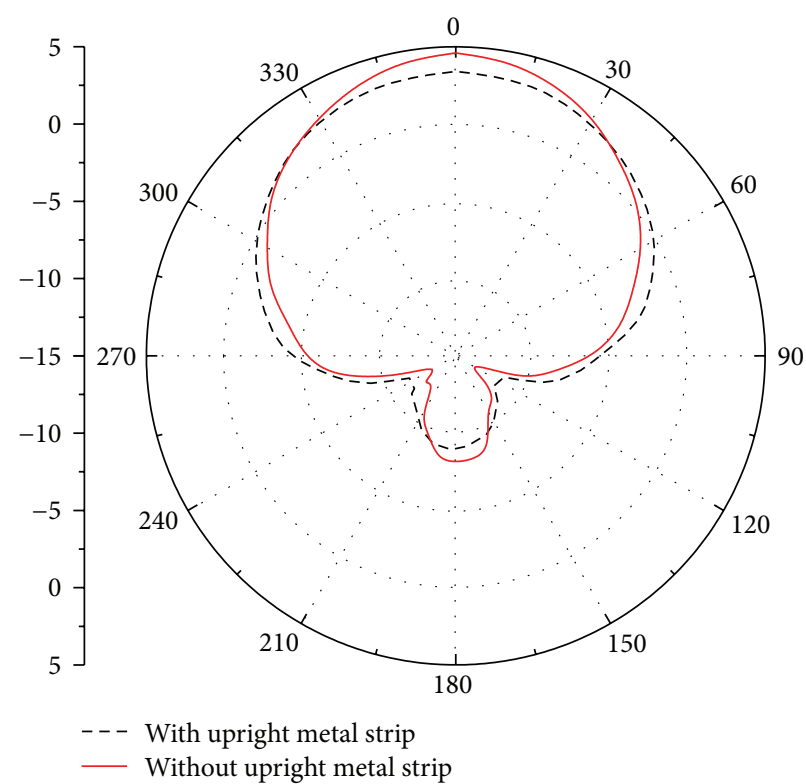

Figure 4: Simulated radiation pattern of the L1 band antenna.

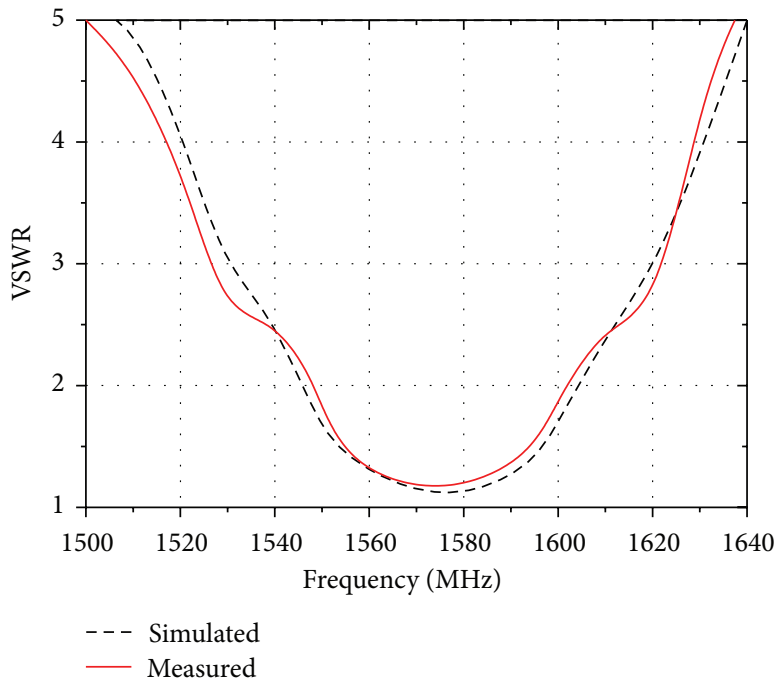

(a)

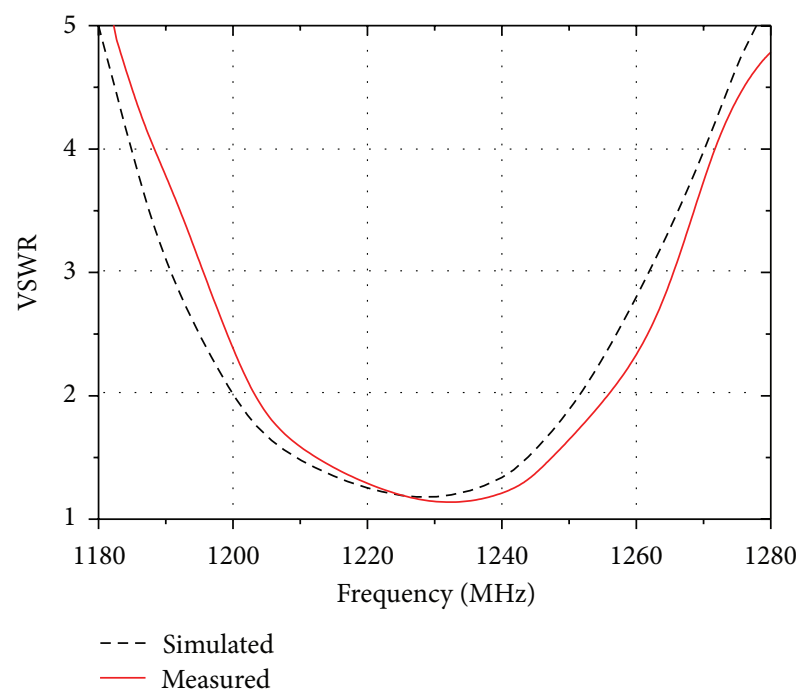

(b)

FIGURE 5: Simulated and measured VSWR of the proposed dual-band CP antenna: (a) L1 band, (b) L2 band. 


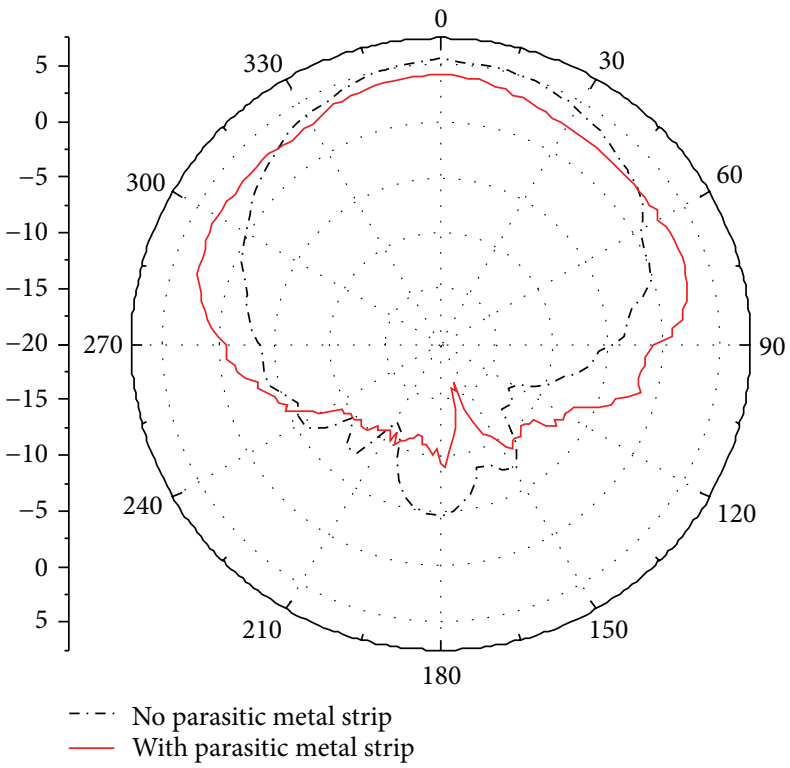

(a)

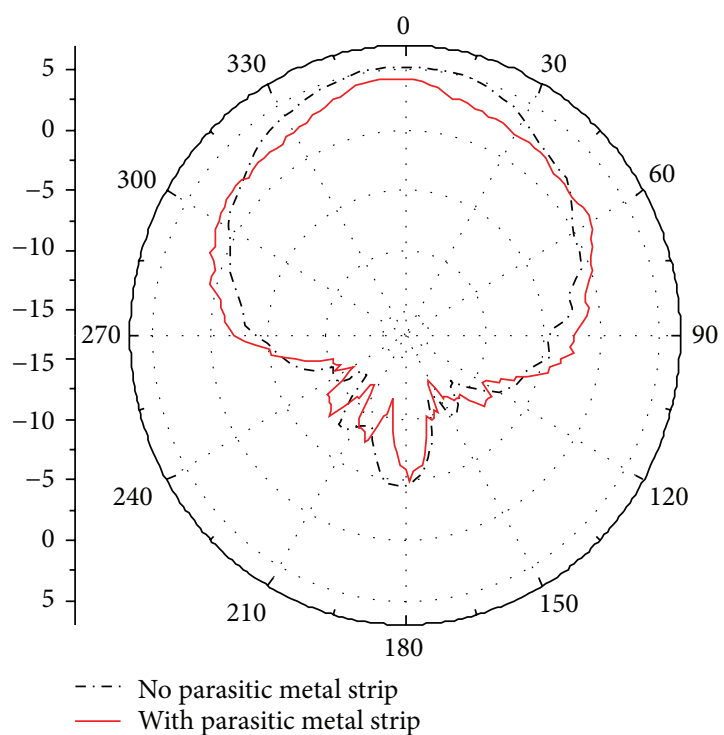

(b)

Figure 6: 2D patterns in $x-z$ plane of the proposed dual-band CP antenna: (a) L1 band, (b) L2 band.

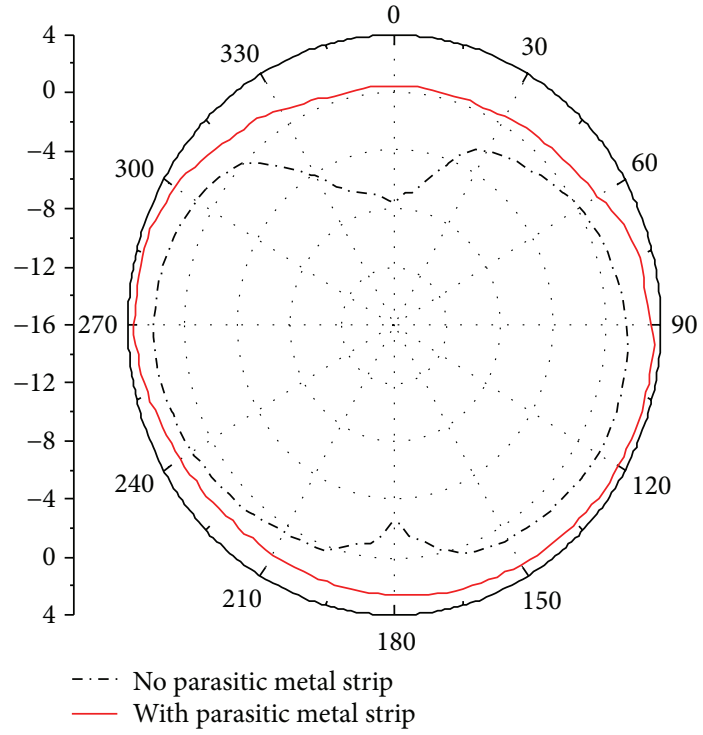

(a)

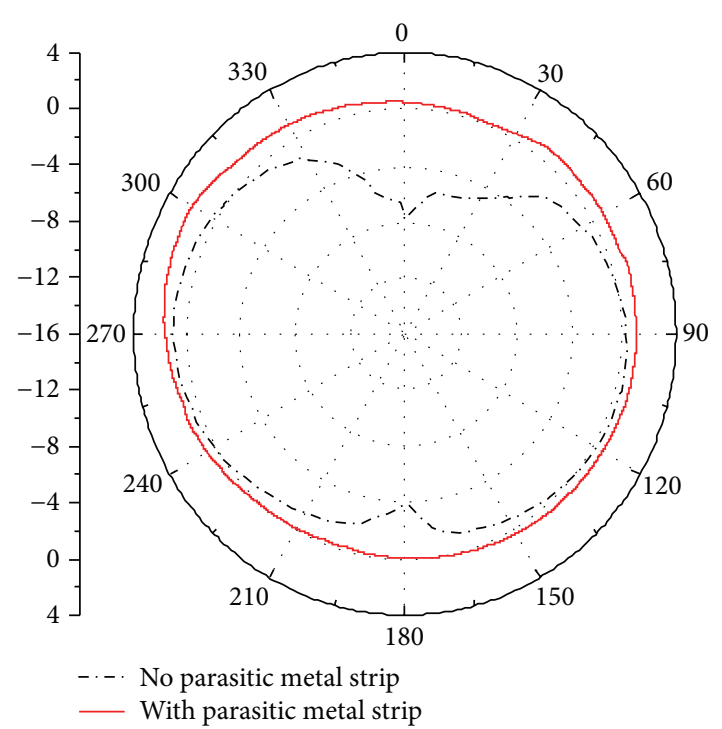

(b)

Figure 7: 2D patterns in $x-y$ plane at $\theta=70^{\circ}$ of the proposed dual-band CP antenna: (a) L1 band, (b) L2 band.

that the two parasitic metal strip elements work as a director and they change the pattern a lot, especially in the $x-z$ plane. To view the difference in detail, the $2 \mathrm{D}$ radiation patterns for the two antennas in the planes of $x-y\left(\theta=70^{\circ}\right)$ are shown in Figure 7. It is clear that the radiation pattern is improved significantly, especially for the nonideal of the pattern in the $x-y$ plane at low angle. The minimum antenna gains at low angle $\left(\theta=70^{\circ}\right)$ are $0.4 \mathrm{dBi}$ and $-0.3 \mathrm{dBi}$ for L1 and L2 bands, and the efficiency is $6.78 \%$ and $63.5 \%$, respectively.
Figure 8 shows the measured AR (axial ratio) with and without parasitic metal strips versus angles for the two antennas. It can be seen that both antennas have a good circular polarization behavior, and the axial ratio for the two antennas with and without metal strips are similar to each other, which means that the parasitic metal strip does not have an obvious influence on circular polarization property. In addition, the isolation between the two antennas is measured as shown in Figure 9. The S21 is $-30 \mathrm{~dB}$ and 


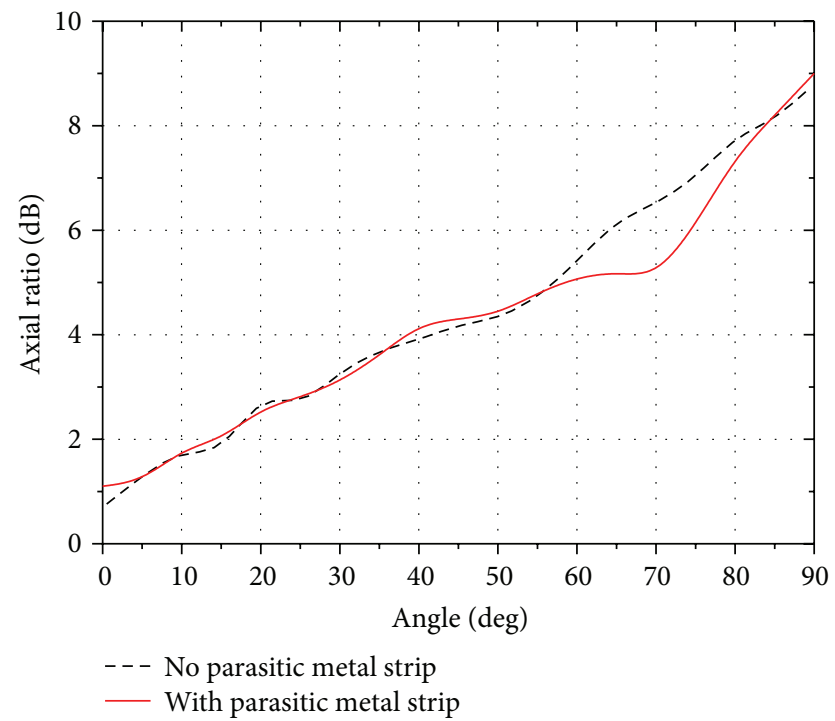

(a)

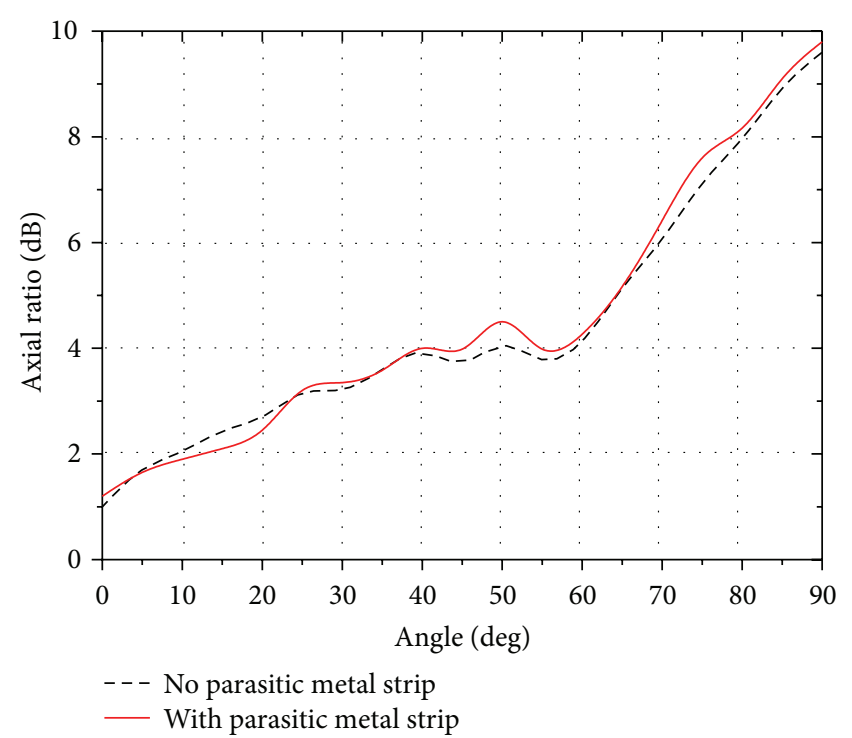

(b)

Figure 8: Axial ratio of the proposed dual-band CP antenna: (a) L1 band, (b) L2 band.

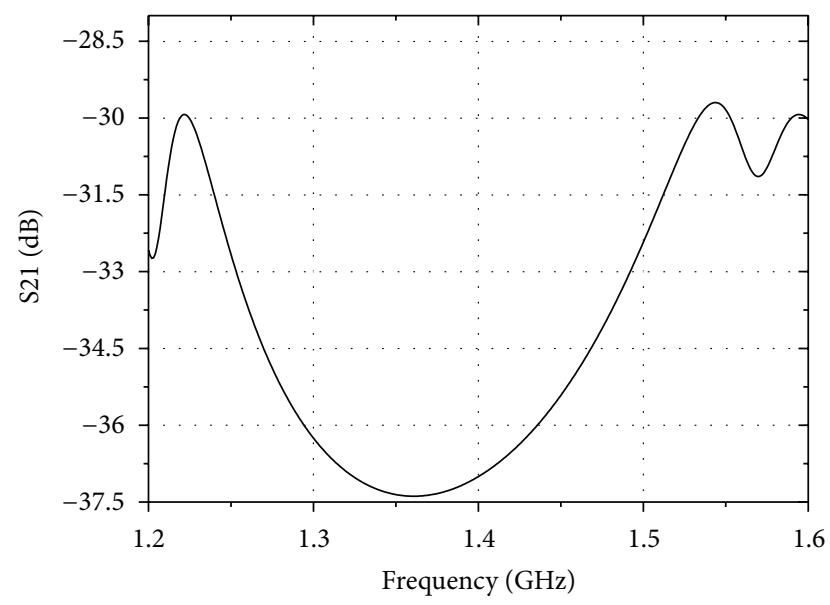

FIGURE 9: S21 versus the frequency for the two antennas.

$-29.6 \mathrm{~dB}$ at the two bands, respectively. It shows that good isolation between the two antennas is obtained.

\section{Conclusions}

A novel method has been introduced to acquire a good near-hemispherical pattern in the two circular polarization microstrip antenna designs. The antennas are stacked with good isolation, and the design is very useful for practical applications.

\section{Acknowledgment}

This work is partly supported by the National Natural Science Foundation of China under Grant no. 61179021.

\section{References}

[1] N. Padros, J. I. Ortigosa, J. Baker, M. F. Iskander, and B. Thornberg, "Comparative study of high-performance gps receiving antenna designs," IEEE Transactions on Antennas and Propagation, vol. 45, no. 4, pp. 698-706, 1997.

[2] L. I. Basilio, R. L. Chen, J. T. Williams, and D. R. Jackson, "A new planar dual-band GPS antenna designed for reduced susceptibility to low-angle multipath," IEEE Transactions on Antennas and Propagation, vol. 55, no. 8, pp. 2358-2366, 2007.

[3] C. M. Su and K. L. Wong, "A dual-band GPS microstrip antenna," Microwave and Optical Technology Letters, vol. 33, no. 4, pp. 238-240, 2002.

[4] S. Egashira and E. Nishiyama, "Stacked microstrip antenna with wide bandwidth and high gain," IEEE Transactions on Antennas and Propagation, vol. 44, no. 11, pp. 1533-1534, 1996.

[5] TOKO America Inc., "Miniature patch antenna for GPS applications," Microwave Journal, vol. 40, no. 8, pp. 116-118, 1997.

[6] X. Lan, "A novel high performance GPS microstrip antenna," in Proceedings of the IEEE Antennas and Propagation Society International Symposium, vol. 2, pp. 988-991, 2000.

[7] T. K. Wuang and J. Huang, "Low-cost antennas for direct broadcast satellite radio," Microwave and Optical Technology Letters, vol. 7, pp. 440-444, 1994.

[8] P. C. Sharma, Desegmentation method and its application to circularly polarized microstrip antennas [Ph.D. thesis], Indian Institute of Technology, Kanpur, India, 1983.

[9] P. C. Sharma and K. C. Gupta, "Analysis and optimized design of single feed circularly polarized microstrip antennas," IEEE Transactions on Antennas and Propagation, vol. 31, no. 6, pp. 949-955, 1983. 

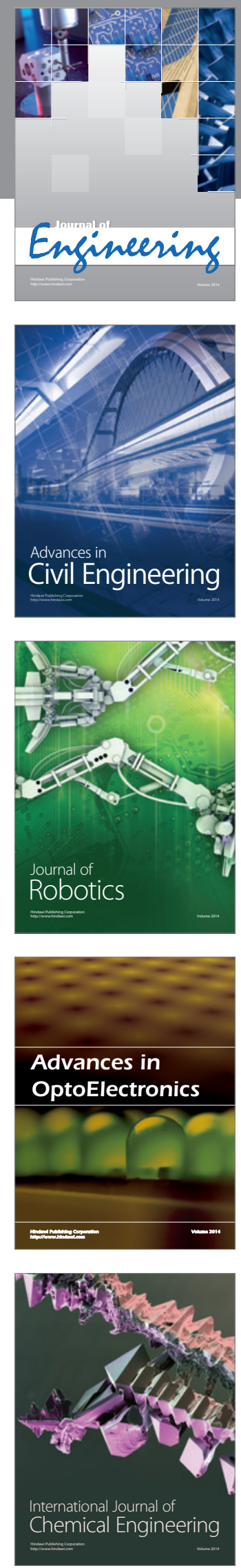

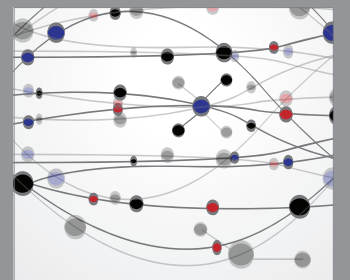

The Scientific World Journal
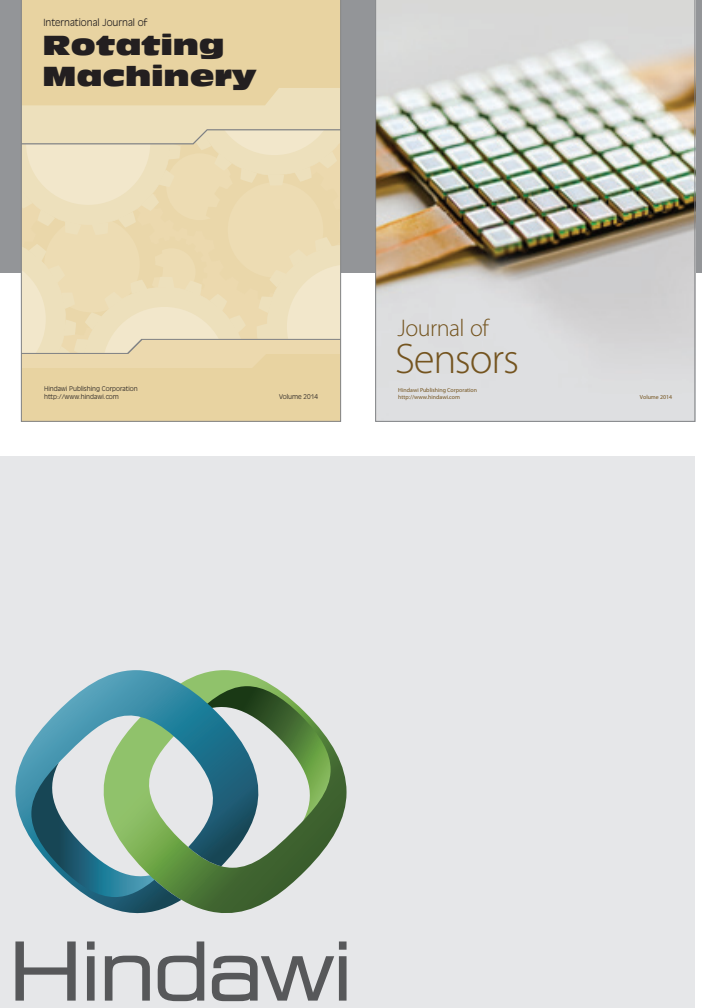

Submit your manuscripts at http://www.hindawi.com
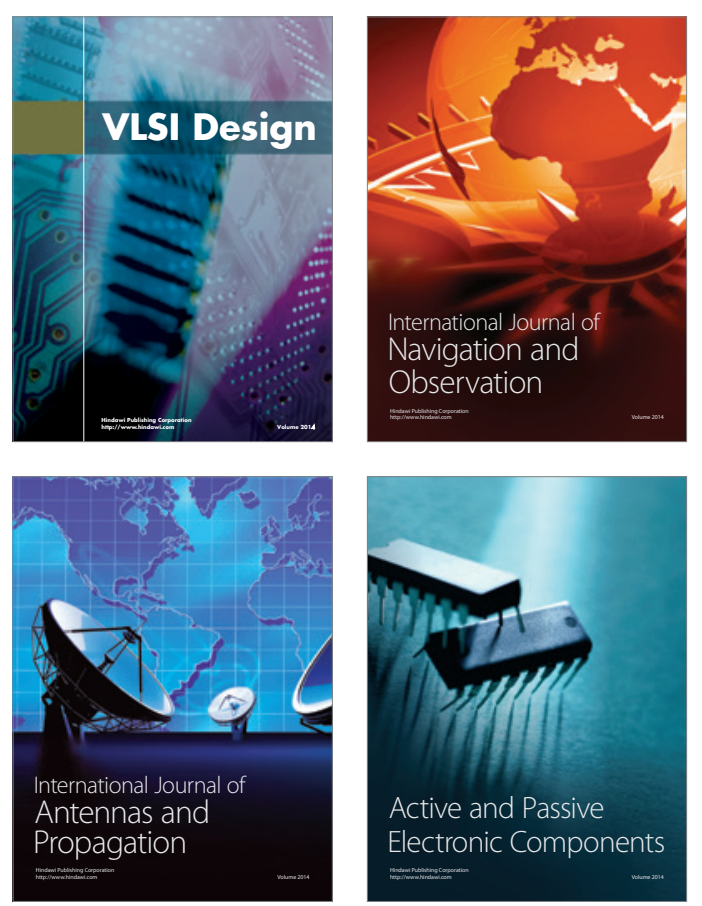
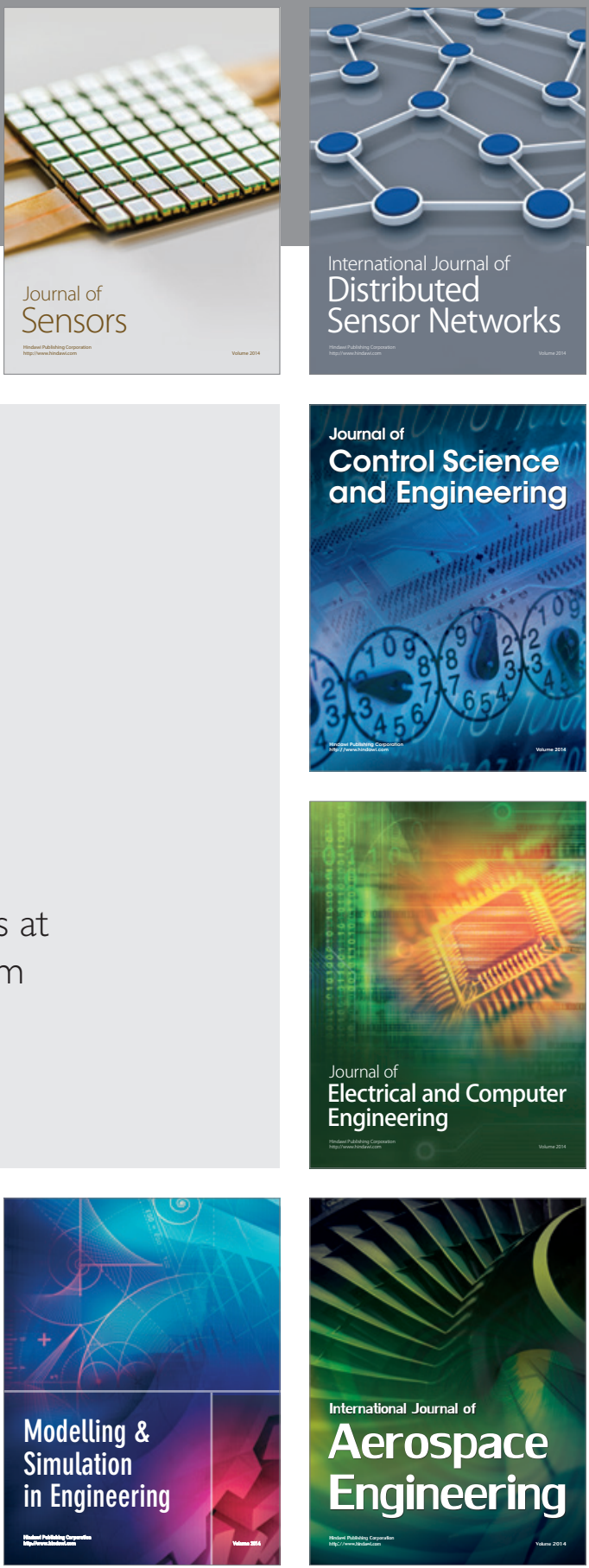

Journal of

Control Science

and Engineering
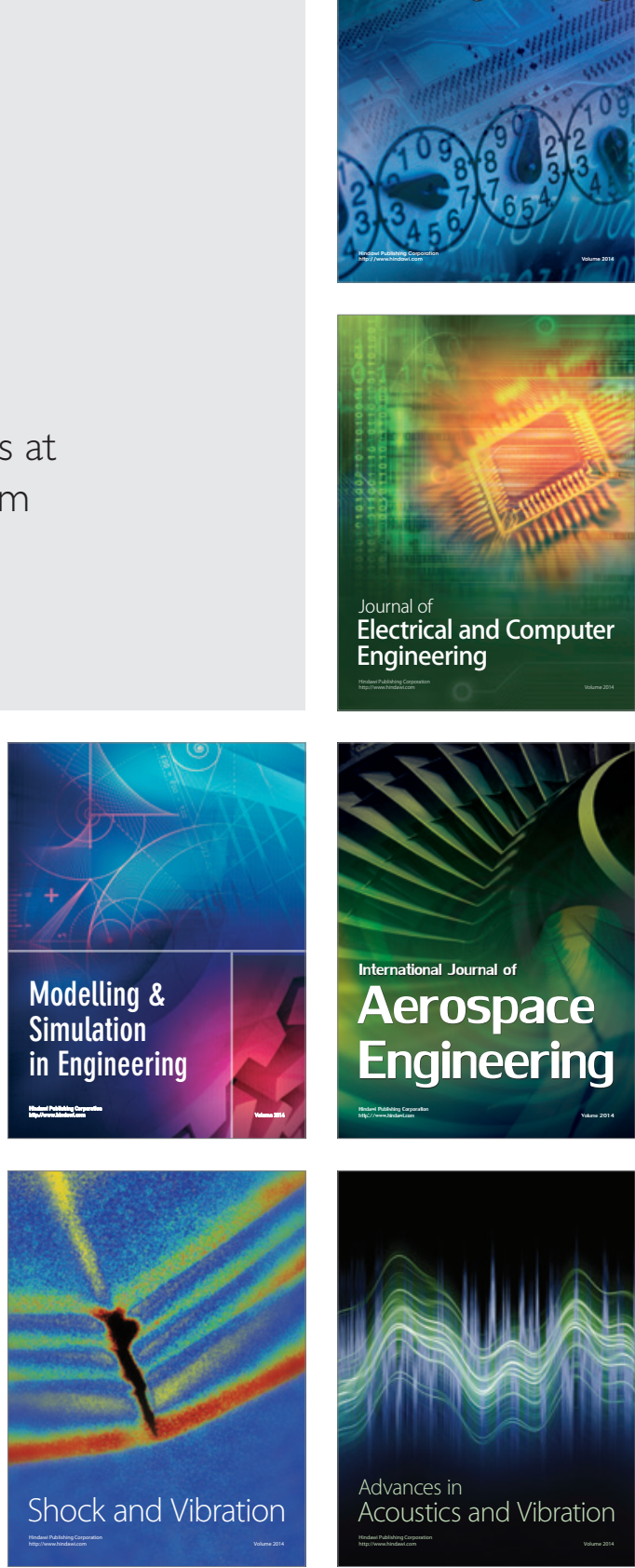